\title{
Correlation of Asymmetry Indices Measured by Arterial Spin-Labeling MR Imaging and SPECT in Patients with Crossed Cerebellar Diaschisis
}

\author{
K.M. Kang, C.-H. Sohn, B.S. Kim, Y.I. Kim, S.H. Choi, T.J. Yun, J.-h. Kim, S.-W. Park, G.J. Cheon, and M.H. Han
}

\begin{abstract}
BACKGROUND AND PURPOSE: Crossed cerebellar diaschisis, not only a secondary result of supratentorial infarction but also an indicator of clinical outcomes, has frequently been reported on PET and SPECT but has been rarely described with arterial spin-labeling MR imaging. The purpose of this study was to determine the ability of arterial spin-labeling MR imaging to evaluate crossed cerebellar diaschisis compared with that of SPECT. To our knowledge, this is the first study to validate arterial spin-labeling in crossed cerebellar diaschisis by using SPECT as a reference standard.
\end{abstract}

MATERIALS AND METHODS: This study included 16 patients in whom crossed cerebellar diaschisis was shown on SPECT and 10 control subjects in whom crossed cerebellar diaschisis was not shown on SPECT. During the qualitative analysis, asymmetric cerebellar perfusion on arterial spin-labeling was divided into 1 of the following 3 grades by 2 blinded observers: the affected cerebellum was isointense compared with the unaffected cerebellum (grade I), it was slightly hypointense (grade II), or it was markedly hypointense (grade III). In the quantitative analysis, asymmetry indices were calculated by using SPECT and arterial spin-labeling images. For statistical analysis, $\kappa$ statistics, the interobserver correlation coefficient, the independent $t$ test, Pearson correlation, and linear regression analysis were used.

RESULTS: Almost all the diagnoses of crossed cerebellar diaschisis on SPECT were noted on arterial spin-labeling in both qualitative and quantitative analyses with good interobserver agreement ( $\kappa=0.961$; interobserver correlation coefficient, 0.806$)$. The mean asymmetry index of arterial spin-labeling $(26.06 \pm 9.00)$ was significantly larger than that for SPECT $(15.28 \pm 5.34 ; P<.001)$. There was a significant positive correlation between the asymmetry indices obtained for SPECT and those for arterial spin-labeling $(r=0.77[95 \% \mathrm{Cl}, 0.443-0.916] ; P<.001)$. The relationship of asymmetry indices between SPECT and arterial spin-labeling $(x, y)$ was calculated as $y=6.2131+1.2986 x\left(R^{2}=0.592 ; P<.001\right)$.

CONCLUSIONS: Arterial spin-labeling can be a noninvasive alternative to SPECT for evaluating crossed cerebellar diaschisis.

ABBREVIATIONS: $\mathrm{Al}=$ asymmetry index; $\mathrm{ASL}=$ arterial spin-labeling; $\mathrm{CCD}=$ crossed cerebellar diaschisis

$\mathbf{C}^{\mathrm{r}}$ rossed cerebellar diaschisis (CCD) is decreased blood flow and metabolism contralateral to a damaged supratentorial area. ${ }^{1}$ It is believed that the most likely mechanism of CCD is an interruption of the corticopontocerebellar fibers. ${ }^{1-3}$ The deafferentation and trans-

Received December 17, 2014; accepted after revision February 20, 2015.

From the Departments of Radiology (K.M.K., C.-H.S., B.S.K., S.H.C., T.J.Y., J.-h.K., M.H.H.) and Nuclear Medicine (Y.I.K., G.J.C.), Seoul National University Hospital, Seoul, Republic of Korea; Department of Radiology (K.M.K., C.-H.S., B.S.K., S.H.C., T.J.Y., J.-h.K., S.-W.P., M.H.H.), Seoul National University College of Medicine, Seoul, Republic of Korea; Institute of Radiation Medicine (C.-H.S., S.H.C., M.H.H.), Seoul National University Medical Research Center, Seoul, Republic of Korea; and Department of Radiology (S.-W.P.), Seoul National University Boramae Hospital, Seoul, Republic of Korea.

Please address correspondence to Chul-Ho Sohn, MD, Department of Radiology, Seoul National University Hospital, 101, Daehangno, Jongno-gu, Seoul 110-744, South Korea; e-mail: neurorad63@gmail.com

三 Indicates article with supplemental on-line table.

http://dx.doi.org/10.3174/ajnr.A4366 neural metabolic depression of the affected cerebellar hemisphere are usually associated with contralateral supratentorial stroke, epilepsy, infection, or a tumor. ${ }^{4-8} \mathrm{CCD}$ is not only a secondary result of supratentorial infarction but also a prognostic indicator of neurologic improvement and clinical outcomes after infarction. ${ }^{9-13}$ For example, in one study, CCD in the chronic stage was associated with neurologic improvement after infarction in the territory of the middle cerebral artery. ${ }^{12}$ In another study, CCD in the early subacute stage of supratentorial infarction indicated a worse clinical outcome. ${ }^{10}$ Furthermore, a PET study of acute stroke that evaluated multiple time points revealed that after reperfusion with thrombolysis, CCD recovery was observed in patients with relatively small infarcts and was strongly associated with clinical outcome measures. ${ }^{11}$

Since CCD was first described in a PET study conducted by Baron et $\mathrm{al}^{4}$ in 1981, PET and SPECT have been the methods of choice in most studies for documenting changes in CBF and me- 
tabolism during CCD. ${ }^{1,9,11,14-18}$ Regarding perfusion MR imaging, there have been 2 studies performed by using DSC MR perfusion imaging. Yamada et $\mathrm{al}^{19}$ reported that a lower regional cerebellar blood volume was observed in the affected cerebellum, and researchers in the other study ${ }^{20}$ identified the frequency of CCD observed in acute stroke by using time-to-peak maps and calculated the reduction by using CBF maps. However, another study reported that DSC MR perfusion at $1.5 \mathrm{~T}$ was not suited to show CCD after stroke because of poor accuracy compared with that of PET. ${ }^{21}$

Recently, arterial spin-labeling (ASL) was introduced as a noninvasive method for assessing cerebral hemodynamics. This method uses endogenous arterial water as a freely diffusible tracer labeled by radiofrequency pulses. ${ }^{22,23}$ In contrast to DSC contrast MR perfusion imaging, PET, and SPECT, ASL imaging is a completely noninvasive method that does not require the injection of exogenous material such as gadolinium-based contrast or radioisotopes. In addition, CBF values derived by using ASL have been shown to correlate with those of SPECT in patients with Moyamoya disease ${ }^{24}$ and with those of PET in patients with symptomatic ICA occlusion. ${ }^{25}$

Although the results of a recent study suggested that CCD can be detected via ASL MR imaging, this finding was not validated against a reference method. ${ }^{26}$ Therefore, the purpose of our study was to investigate the value of ASL MR imaging for the evaluation of CCD compared with that of SPECT, which served as the standard of reference in patients with contralateral supratentorial lesions.

\section{MATERIALS AND METHODS Study Population}

This retrospective study was approved by the Seoul National University Hospital institutional review board, and the need for informed consent was waived. From October 2011 to October 2014, among 209 SPECT examinations in patients with clinically suspected hemispheric stroke, we identified those who met the following inclusion criteria: 1) CCD on SPECT (164 cases were excluded), 2) SPECT and ASL performed within 1 day of one another (20 cases were excluded because of the lack of ASL MR perfusion imaging; 7 cases were excluded because of a long interval between SPECT and ASL), 3) no structural abnormality in the cerebellum or brain stem on MR imaging (1 patient was excluded), and 4) satisfactory image quality (1 patient was excluded). Finally, 16 patients with 16 sets of SPECT and ASL examinations were included in this study as the CCD-positive group. We also included 10 age-matched control subjects (CCDnegative group) to demonstrate the diagnostic performance of ASL. The inclusion criteria for the control group were as follows: 1) supratentorial lesion with no evidence of CCD on SPECT and 2) SPECT and ASL within 1 day of one another.

\section{ASL MR Technique}

Each patient underwent an MR examination by a 1.5T unit (Signa HDXT; GE Medical Systems, Milwaukee, Wisconsin) with an 8-channel head coil to acquire ASL perfusion MR imaging. The imaging protocol included T1-weighted, T2-weighted, fluid-attenuated inversion recovery, and diffusion-weighted imaging $\left(b=0\right.$ and $\left.1000 \mathrm{~s} / \mathrm{mm}^{2}\right)$, 3D-TOF intracranial MRA, and contrast-enhanced neck MRA (On-line Table).

The ASL protocol used was a pseudocontinuous ASL, which significantly increased the flow-labeling efficacy in a single-coil setting. ${ }^{27,28}$ The sequence provided by GE Healthcare performed pseudocontinuous ASL for 1.5 seconds followed by a post-spinlabeling delay of 1.5 seconds. Background suppression was performed by using saturation pulses. ${ }^{29}$ Saturation was performed with crusher gradients applied inferior to the labeling plane, allowing for an increase in the sharpness of the bolus. The image acquisition consisted of a stack of interleaved FSE spiral readouts, each of which lasted $4 \mathrm{~ms}$. Each spiral arm included 512 sampling points in the $k$-space, and a total of 8 interleaves (arms) were acquired separately. In addition, reconstruction was performed by using a Fourier transform algorithm after the $k$-space data were regridded into a $64 \times 64$ matrix (TR, $1345 \mathrm{~ms}$; TE, $5 \mathrm{~ms}$; flip angle, $155^{\circ}$; sections, 32 ; section thickness, $5 \mathrm{~mm}$; intersection gap, 0 $\mathrm{mm}$; field of view, $240 \times 240 \mathrm{~mm}$; matrix, $256 \times 256$; acquired signals, 3 ; echo-train length, 1 ; voxel resolution, $3.8 \times 3.8 \times 5.0$ $\mathrm{mm}$ ). Image reconstruction was performed according to standard GE reconstruction by using codes written in Interactive Data Language on a virtual machine associated with the scanner. The images were filtered by using Fermi windowing for ringing artifact reduction. Grad warp was not applied.

\section{Brain Perfusion SPECT Acquisition and Analysis}

Brain perfusion SPECT was performed by using a triple-head gamma camera (Triad XLT 9; Trionix Research Laboratory, Twinsburg, Ohio) equipped with low-energy ultra-high-resolution fan-beam collimators. Technetium Tc99m-hexamethylpropyleneamine oxime $(9.25 \mathrm{MBq} / \mathrm{kg})$ was injected intravenously for basal SPECT, and images were acquired after 5 minutes of radiotracer injection. Forty step-and-shoot images were acquired for $20-25$ seconds per step, with intervals of $3^{\circ}$. Acetazolamide (20 $\mathrm{mg} / \mathrm{kg}$ ) was injected 10 minutes before the end of the basal scan, and technetium Tc-99 m-hexamethylpropyleneamine oxime $(18.5 \mathrm{MBq} / \mathrm{kg}$ ) was injected again at the end of the basal scan acquisition. Five minutes after technetium Tc-99 m-hexamethylpropyleneamine oxime reinjection, diamox SPECT was started without position change. All SPECT images were reconstructed on $128 \times 128$ matrices by using a filtered back-projection method with a Metz filter. CCD was assessed on the opposite side of the cortical infarction on basal SPECT by a nuclear medicine physician. CCD was diagnosed in patients who showed significantly less uptake in the cerebellum on the contralateral side. To assess the cerebellar hemispheric asymmetry index (AI), circular ROIs, measuring $25 \mathrm{~mm}$ in diameter, were placed in the affected and mirrored unaffected cerebellar hemispheres. The degree of CCD was measured on a section of axial scan representing the greatest cerebellar asymmetry. ${ }^{26}$ The AI was calculated between the affected cerebellar hemisphere $(A)$ and the unaffected cerebellar hemisphere $(U)$ as follows ${ }^{1,19,20}$ :

$$
\mathrm{AI}=(U-A) / U \times 100 \% .
$$

\section{ASL Image Analysis}

In the qualitative analysis, 2 neuroradiologists (K.M.K. and B.S.K.) who were blinded to the presence or absence of CCD 


\begin{tabular}{|c|c|c|c|c|c|c|c|c|c|}
\hline \multirow{2}{*}{$\begin{array}{l}\text { Patient } \\
\text { No. }\end{array}$} & \multirow[b]{2}{*}{ Age (y) } & \multirow[b]{2}{*}{ Sex } & \multirow[b]{2}{*}{ Cause } & \multirow{2}{*}{$\begin{array}{c}\text { Supratentorial Lesion } \\
\text { Type }\end{array}$} & \multirow{2}{*}{$\begin{array}{l}\text { Affected Side } \\
\text { of Cerebellum }\end{array}$} & \multirow{2}{*}{$\begin{array}{l}\text { Qualitative } \\
\text { Analysis, } \\
\text { Grade }\end{array}$} & \multicolumn{2}{|c|}{$\begin{array}{c}\text { Quantitative } \\
\text { Analysis, Al (\%) } \\
\end{array}$} & \multirow{2}{*}{$\begin{array}{c}\text { Interval Between } \\
\text { SPECT and ASL, } \\
\text { Days }\end{array}$} \\
\hline & & & & & & & SPECT & ASL & \\
\hline 1 & 54 & $M$ & ICA occlusion & Chronic infarction & Left & III & 16.96 & 37.85 & 0 \\
\hline 2 & 28 & $M$ & MMD & Chronic infarction & Left & III & 15.5 & 32.86 & 0 \\
\hline 3 & 33 & $\mathrm{~F}$ & MMD & Previous ICH & Left & II & 11.5 & 14.2 & 0 \\
\hline 4 & 32 & $M$ & MMD & Chronic infarction & Right & III & 14.9 & 20.14 & 0 \\
\hline 5 & 71 & $\mathrm{~F}$ & ICA occlusion & Chronic infarction & Right & III & 7.79 & 19.66 & 0 \\
\hline 6 & 79 & $\mathrm{~F}$ & ICA occlusion & $\begin{array}{l}\text { Subacute to chronic } \\
\text { infarction }\end{array}$ & Left & III & 24.13 & 36.31 & 0 \\
\hline 7 & 50 & $\mathrm{~F}$ & MMD & $\begin{array}{l}\text { Subacute to chronic } \\
\text { infarction }\end{array}$ & Right & II & 7.29 & 13.74 & 1 \\
\hline 8 & 41 & $\mathrm{~F}$ & MMD & Previous ICH & Right & III & 17.33 & 32.79 & 1 \\
\hline 9 & 44 & $M$ & MMD & Chronic infarction & Left & ॥ & 17 & 19.91 & 1 \\
\hline 10 & 27 & $M$ & MMD & Chronic infarction & Left & III & 24.5 & 67.64 & 1 \\
\hline 11 & 21 & $\mathrm{~F}$ & MMD & Chronic infarction & Left & III & 15.5 & 20.87 & 1 \\
\hline 12 & 43 & $\mathrm{~F}$ & MMD & Previous ICH & Left & III & 22.97 & 39.78 & 1 \\
\hline 13 & 66 & $M$ & ICA occlusion & Chronic infarction & Left & II & 16.28 & 21 & 1 \\
\hline 14 & 61 & $M$ & MMD & Previous ICH & Left & III & 10.2 & 16.3 & 1 \\
\hline 15 & 20 & $\mathrm{~F}$ & MMD & Chronic infarction & Left & III & 10.24 & 28.09 & 1 \\
\hline 16 & 56 & $\mathrm{~F}$ & MMD & Chronic infarction & Left & III & 12.43 & 25.83 & 1 \\
\hline
\end{tabular}

Note:-F indicates female; M, male; MMD, Moyamoya disease; ICH, intracranial hemorrhage.

and the side of the supratentorial stroke evaluated the ASL images from the CCD-positive and CCD-negative groups in random order. The observers determined the presence or absence of CCD and the side of the affected cerebellum, which showed asymmetrically decreased perfusion compared with that of the unaffected cerebellum on ASL perfusion MR imaging. For the blind study, the cerebellum was evaluated from bottom to top. The signal intensity of the affected cerebellum was divided into 1 of the 3 following grades: grade I indicates that the affected cerebellum was isointense to the unaffected cerebellum; grade II indicates that the affected cerebellum was slightly hypointense to the unaffected cerebellum; and grade III indicates that the affected cerebellum was markedly hypointense to the unaffected cerebellum. A grade of II or III was considered to be positive for the diagnosis of CCD. Two readers were trained before the study; they were shown examples of CCD and examples of what would be graded as I versus II versus III.

In the quantitative analysis of the CCD-positive group, the CBF map from ASL was used to compare the affected cerebellum with the unaffected cerebellum. The circular ROIs were drawn manually on the ASL MR images by using the same method applied for the SPECT images. All ROIs were placed to avoid the major vessels and cerebellar vermis. The degree of hypoperfusion was calculated by using the same formula as that for the SPECT AI.

To investigate correlations between cerebellar AIs and supratentorial lesion volume, we computed the volume of supratentorial lesion on FLAIR imaging by using commercial software (nordicICE, and nordicTumorEx [NordicNeuroLab, Bergen, Norway], respectively) for each section that displayed a signal-intensity abnormality by manual segmentation.

\section{Statistical Analysis}

The interrater agreements for the presence of CCD in the qualitative analysis based on tertiary (grade I, II, and III) data were assessed by using $\kappa$ statistics. A $\kappa$ value of $<0.20$ indicated poor agreement, $0.21-0.40$ indicated fair agreement, $0.41-0.60$ indicated moderate agreement, $0.61-0.80$ indicated good agreement, and $>0.81$ indicated excellent agreement. In addition, the diagnostic performance of each observer was assessed by using receiver operating characteristic curve analysis. The sensitivity, specificity, positive predictive value, and negative predictive value for ASL were calculated with respect to SPECT.

For the quantitative results of the CCD-positive group, the Kolmogorov-Smirnov test was used to determine whether the AI values were normally distributed. Interobserver reproducibility was assessed by the interobserver correlation coefficient. ${ }^{30}$ An interobserver correlation coefficient value of $<0.40$ indicated poor reproducibility, $0.40-0.59$ indicated fair reproducibility, $0.60-0.74$ indicated good reproducibility, and $>0.74$ indicated excellent reproducibility. ${ }^{31}$ An independent $t$ test was used to compare significant differences between the AIs from ASL by observers 1 and 2 and between the AIs from SPECT and ASL. Linear regression and Pearson correlation coefficients were used to evaluate the correlation between the AIs from SPECT and ASL and between cerebellar AIs and supratentorial lesion volumes. ${ }^{27,32}$ Significance for each test was set at a $P$ value of $<.05$. Commercially available software (MedCalc for Windows, version 11.1.1.0; MedCalc Software, Mariakerke, Belgium) was used for the analysis.

\section{RESULTS}

The clinical characteristics and results of the qualitative and quantitative analyses are summarized in the Table. The CCD-positive group consisted of 16 patients ( 7 men and 9 women; mean age [ \pm standard deviation], $45 \pm 18$ years; range, $20-79$ years). The patients had Moyamoya disease $(n=12)$ or unilateral proximal ICA occlusion $(n=4)$. Each patient presented unilateral ischemic or hemorrhagic stroke on MR imaging. The ASL and SPECT examinations were performed because of subacute to chronic in- 


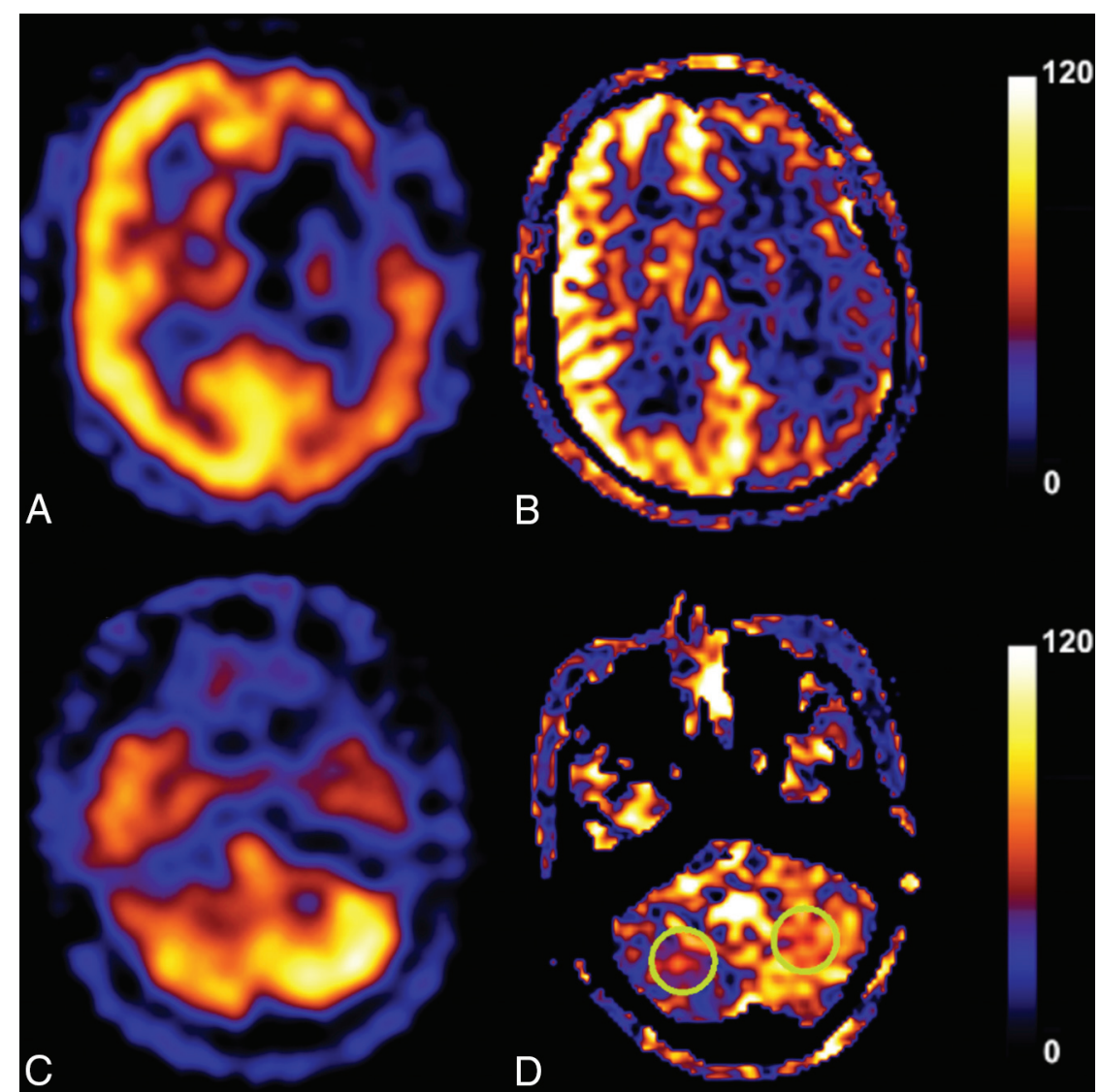

FIG 1. A 41-year-old female patient with previous intracranial hemorrhage caused by Moyamoya disease. The SPECT ( $A$ and $C$ ) and arterial spin-labeling ( $B$ and $D$ ) images show decreased CBF in the left cerebrum associated with right cerebellar diaschisis. The signal intensity of the affected right cerebellum was markedly hypointense to that of the unaffected left cerebellum (grade III). Two circular ROls of $25 \mathrm{~mm}$ in diameter were placed in the affected and mirrored unaffected cerebellar hemispheres on a section of axial scan representing the greatest cerebellar asymmetry.

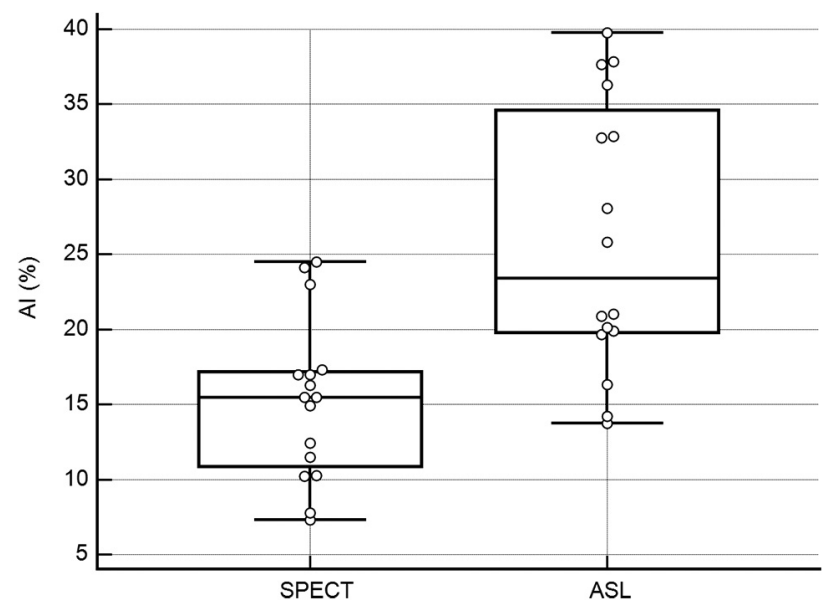

FIG 2. Box-and-whisker plots show the distributions, medians, and ranges of asymmetry indices (Als) for arterial spin-labeling (ASL) and SPECT. The mean Al for ASL $(26.06 \% \pm 9.00 \%)$ was significantly different from that for SPECT $(15.28 \% \pm 5.34 \% ; P<.0001)$.

farction $(n=2)$, chronic infarction $(n=10)$, or previous intracranial hemorrhage $(n=4)$. The CCD-negative group consisted of 10 patients ( 2 men and 8 women; mean age, $46 \pm 15$ years; range, 23-70 years). Each control subject had unilateral ischemic or hemorrhagic stroke as a result of Moyamoya disease $(n=8)$ or unilateral ICA occlusion $(n=2)$ without CCD on SPECT.

\section{Qualitative Analysis}

Asymmetric cerebellar hypointensity suggestive of hypoperfusion on ASL was observed in each of the 16 patients by observer 1 and in 15 by observer 2 . Therefore, the sensitivity, specificity, positive predictive value, and negative predictive value for observer 1 were all $100 \%$ for the presence of CCD. Observer 2 exhibited rates of $93.75 \%$ sensitivity (15 of 16 patients), 100\% specificity (10 of 10 patients), $100 \%$ positive predictive value (15 of 15 patients), and 90.91\% negative predictive value (10 of 11 patients). The laterality of the affected cerebellum on ASL was in agreement with SPECT results for all patients by observer 1 and for 15 patients by observer 2. The grades of signal intensity in the affected cerebellum classified by observers 1 and 2 were identical in all cases except for the single false-negative evaluation by observer 2 . Observer 1 classified the signal intensity of the affected cerebellum as grade III in 13 cases and grade II in 3 cases; observer 2 classified the signal intensity of the affected cerebellum as grade III in 13 cases, grade II in 2 cases, and grade $I$ in 1 case (Fig 1 ). Therefore, the interrater agreement was excellent $(\kappa=0.961)$.

\section{Quantitative Analysis}

For the AIs measured by using ASL images from the CCD-positive group, the interobserver agreement was excellent (interobserver correlation coefficient between observers 1 and 2, 0.806). The mean AIs \pm standard deviations were $24.36 \% \pm 8.30 \%$ for observer 1 and $27.75 \pm 10.61$ for observer 2 . There were no significant differences between the mean AIs from ASL by observers 1 and $2(P=.34)$. We used the mean values of the measurements from observers 1 and 2 to define the AIs for ASL. There was a significant difference between the mean AIs from SPECT and ASL $(P<.001)$. The mean AI from ASL $(26.06 \% \pm 9.00 \%)$ was significantly larger than that from SPECT $(15.28 \% \pm 5.34 \%)$ (Fig 2). There was a significant positive correlation between the AIs obtained from SPECT and ASL $(r=0.77$ [95\% CI, 0.443-0.916]; $P<.001)$. The regression line for this relationship $(x=$ AI from SPECT; $y=$ AI from ASL) was calculated as $y=6.2131+1.2986 x\left(R^{2}=0.592 ; P<.001\right)$ (Fig 3).

The mean volume of supratentorial lesions was $28.12 \pm 25.66$ $\mathrm{cm}^{3}$. Regarding the relationship of cerebellar AI and supratentorial lesion volume, there was no significant correlation between AIs from SPECT and the volumes $(r=-0.100$ [95\% CI, -0.568 


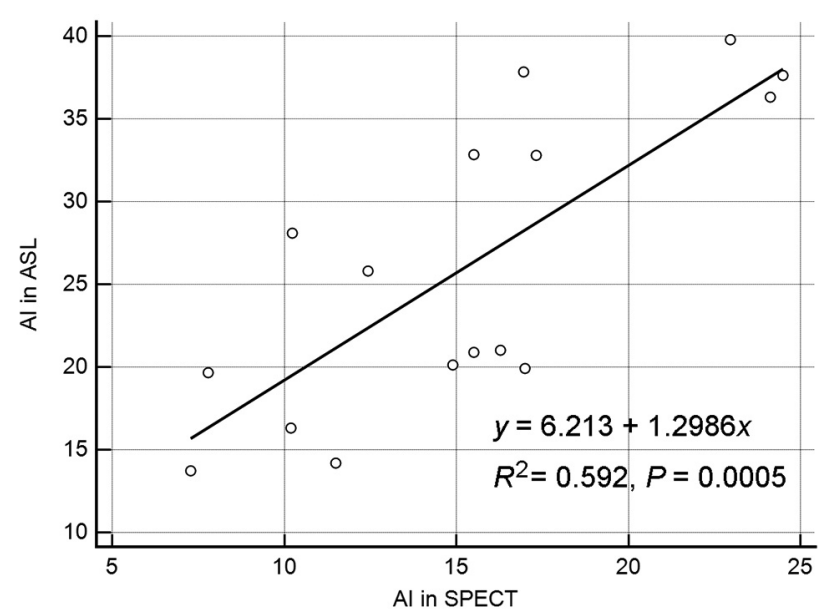

FIG 3. Scatter diagram of the correlations between Als for ASL and SPECT. The Als for SPECT and ASL exhibited a significant positive correlation ( $r=0.77$ [95\% Cl, 0.443-0.916]; $P=.0005)$.

to 0.416$] ; P=.711)$ or between AIs from ASL and the volumes ( $r=-0.036$ [95\% CI, -0.522 to 0.469 ]; $P=.896$ ). The relationships of the AIs between supratentorial lesion volume and the AI obtained from SPECT $(x, y)$ and between the volume and the AI obtained from ASL $(x, y)$ were calculated as $y=15.851+-0.202 x$ $\left(R^{2}=0.010 ; P=.711\right)$ and $y=26.40+-01012 x\left(R^{2}=0.001\right.$; $P=.896)$, respectively.

\section{DISCUSSION}

CCD is a common result of cerebral stroke. Several previous studies have suggested that CCD is not only an important prognostic factor for stroke recovery but is also associated with cognitive function and the development of vascular dementia. ${ }^{10,13,33-35}$ Therefore, the quantification of CCD can be used as a clinical prognostic indicator. However, few studies have reported a correlation between the clinical outcome and treatment response in patients and the quantitative value of CCD. ${ }^{10-13,18,20}$ One reason is that PET and SPECT have been used as criterion standards for diagnosing and studying CCD, and the need to inject radioisotopes and the exposure to radiation have made long-term follow-up difficult. However, noninvasive ASL MR perfusion imaging has emerged as a valuable method that can be used to obtain brain-flow information noninvasively and repeatedly. ${ }^{36}$ Therefore, in this study we aimed to determine the ability of ASL to assess CCD compared with the reference method, SPECT, which has been widely used to diagnose and study CCD. Almost all diagnoses of CCD on SPECT were also noted on ASL in both qualitative and quantitative analyses with good interobserver agreement. In addition, a significant positive correlation was observed between the AIs from ASL and SPECT. Although one earlier study revealed that $\mathrm{CCD}$ can be detected on $\mathrm{ASL},{ }^{26}$ this study is the first to validate ASL in CCD by using SPECT as a reference standard.

In the qualitative analysis with ASL, CCD on ASL was observed in each of the 16 patients by observer 1 and in 15 of the patients by observer 2. Except for the single false-negative case by observer 2 , the 2 observers agreed perfectly regarding the grade for each case. Most CCD-positive cases (13 of 16 [81\%]) were classified as grade III by both observers. The false-negative case was classified as grade I by observer 2 and as grade II by observer 1 . In the quanti- tative analysis, the interobserver correlation coefficient was also excellent between the 2 observers. Our results suggest that the visualization and quantification of CCD by using ASL were reproducible across observers.

The mean AI from SPECT $(15.28 \% \pm 5.34 \%)$ in our study was similar to results $(16.0 \% \pm 7.9 \%)$ obtained in a previous study that reported a mean AI for CCD by using DSC MR imaging in patients with subacute to chronic infarction. ${ }^{19}$ However, the mean AI from ASL $(26.06 \% \pm 9.00 \%)$ was significantly larger than that from SPECT $(15.28 \% \pm 5.34 \%)$, and there was a significant positive correlation between the 2 values. In addition, several previous studies reported that measured CBF values were similar between ASL and SPECT and between ASL and DSC MR imaging in patients with Moyamoya disease or carotid stenosis. ${ }^{24,37,38}$ According to these results, the sensitivity of ASL might be greater than that of SPECT for assessing cerebral perfusion during follow-up in patients with CCD and correlating the findings with the clinical course. Therefore, additional study using ASL is necessary to investigate the serial changes in CCD and their clinical importance.

In our study, there were no significant correlations between the AI from SPECT and supratentorial lesion volume or between the AI from ASL and the volume. There were discordant reports relating to the severity of CCD and infarct volume. ${ }^{20,39,40} \mathrm{Al}$ though CCD is reported most often in association with large cerebral hemispheric infarcts, ${ }^{40,41}$ small infarcts could cause CCD. ${ }^{39}$ A few previous studies reported that infarct volume contributes to the development of CCD, but the sample sizes $(n=20$ and 17 , respectively) were too small. ${ }^{11,20}$ In addition, the patient populations in these previous studies were all in the acute stages of stroke. However, our population was in the subacute to chronic infarction $(n=2)$, chronic infarction $(n=10)$, or previous intracranial hemorrhage $(n=4)$ stage. Additional larger studies using ASL may help to establish a correlation between the severity of CCD and infarct volume according to the stage of infarction.

Although ASL MR imaging has evolved methodologically and technically over the past decade, there are still several limitations and confounding factors that affect the quantification of CBF. The measured CBF is influenced by variations in labeling efficiency, arterial transit time, and blood T1. ${ }^{42}$ Despite these confounding factors, ASL MR imaging is a novel and promising technique because of its completely noninvasive nature, easy acquisition, patient tolerance, relatively lower cost, and scanning time. In this study, a postlabeling delay time of 1.5 seconds was used. Although this time is appropriate for healthy subjects, it can be shorter for patients with Moyamoya disease. ${ }^{36}$ We tried to overcome the potential deviations in CBF quantification in ASL by calculating an asymmetry index.

The present study has several limitations. First, this study was retrospective and vulnerable to selection and verification biases. Second, this study used SPECT as a reference standard. Generally, PET has been considered the criterion standard for CBF quantification. However, to date, several studies have used SPECT to show CBF changes in CCD. ${ }^{10,17,43,44}$ In addition, some studies have shown that SPECT can be an alternative method for CBF assessment in patients with cerebrovascular diseases. ${ }^{45,46}$ Finally, because ASL is technique 
dependent, measurement of the AI and its correlation with SPECT can vary according to variations in the labeling delays. This factor is important to know when considering the use of this technique for longitudinal follow-up.

\section{CONCLUSIONS}

In our study, the AIs of CCD obtained by using ASL were reproducible and significantly correlated with those obtained by using SPECT. Therefore, ASL can be a noninvasive alternative to SPECT for identifying CCD and studying the phenomenon and clinical consequences of CCD. Because ASL allows serial imaging without radiation exposure, this technique can facilitate a better understanding of the impact of CCD on disease outcome over the long term.

\section{REFERENCES}

1. Pantano P, Baron JC, Samson Y, et al. Crossed cerebellar diaschisis. Further studies. Brain 1986;109:677-94 CrossRef Medline

2. Meyer JS, Obara K, Muramatsu K. Diaschisis. Neurol Res 1993;15: 362-66 Medline

3. Gold L, Lauritzen M. Neuronal deactivation explains decreased cerebellar blood flow in response to focal cerebral ischemia or suppressed neocortical function. Proc Natl Acad Sci U S A 2002;99: 7699-704 CrossRef Medline

4. Baron JC, Bousser MG, Comar D, et al. "Crossed cerebellar diaschisis" in human supratentorial brain infarction. Trans Am Neurol Assoc 1981;105:459-61 Medline

5. Patronas NJ, Di Chiro G, Smith BH, et al. Depressed cerebellar glucose metabolism in supratentorial tumors. Brain Res 1984;291:93101 CrossRef Medline

6. Thajeb P, Huang KM, Shih CC. Diaschisis in chronic viral encephalitis with Koshevnikov syndrome. J Neuroimaging 1999;9:122-25 Medline

7. Thajeb $\mathrm{P}$, Shih BF, Wu MC. Crossed cerebellar diaschisis in herpes simplex encephalitis. Eur J Radiol 2001;38:55-58 CrossRef Medline

8. Mewasingh LD, Christiaens F, Aeby A, et al. Crossed cerebellar diaschisis secondary to refractory frontal seizures in childhood. Seizure 2002;11:489-93 CrossRef Medline

9. De Reuck J, Decoo D, Lemahieu I, et al. Crossed cerebellar diaschisis after middle cerebral artery infarction. Clin Neurol Neurosurg 1997; 99:11-16 CrossRef Medline

10. Takasawa M, Watanabe M, Yamamoto S, et al. Prognostic value of subacute crossed cerebellar diaschisis: single-photon emission CT study in patients with middle cerebral artery territory infarct. $A J N R$ Am J Neuroradiol 2002;23:189-93 Medline

11. Sobesky J, Thiel A, Ghaemi M, et al. Crossed cerebellar diaschisis in acute human stroke: a PET study of serial changes and response to supratentorial reperfusion. J Cereb Blood Flow Metab 2005;25: 1685-91 CrossRef Medline

12. Serrati C, Marchal G, Rioux P, et al. Contralateral cerebellar hypometabolism: a predictor for stroke outcome? J Neurol Neurosurg Psychiatry 1994;57:174-79 CrossRef Medline

13. Szilágyi G, Vas A, Kerényi L, et al. Correlation between crossed cerebellar diaschisis and clinical neurological scales. Acta Neurol Scand 2012;125:373-81 CrossRef Medline

14. Kim SE, Choi CW, Yoon BW, et al. Crossed-cerebellar diaschisis in cerebral infarction: technetium-99m-HMPAO SPECT and MRI. J Nucl Med 1997;38:14-19 Medline

15. Kamouchi M, Fujishima M, Saku Y, et al. Crossed cerebellar hypoperfusion in hyperacute ischemic stroke. J Neurol Sci 2004;225: 65-69 CrossRef Medline

16. Komaba Y, Mishina M, Utsumi K, et al. Crossed cerebellar diaschisis in patients with cortical infarction: logistic regression analysis to control for confounding effects. Stroke 2004;35:472-76 CrossRef Medline
17. Liu Y, Karonen JO, Nuutinen J, et al. Crossed cerebellar diaschisis in acute ischemic stroke: a study with serial SPECT and MRI. J Cereb Blood Flow Metab 2007;27:1724-32 CrossRef Medline

18. Kajimoto K, Oku N, Kimura Y, et al. Crossed cerebellar diaschisis: a positron emission tomography study with L-[methyl-11C]methionine and 2-deoxy-2-[18F]fluoro-D-glucose. Ann Nucl Med 2007;21: 109-13 CrossRef Medline

19. Yamada H, Koshimoto Y, Sadato N, et al. Crossed cerebellar diaschisis: assessment with dynamic susceptibility contrast MR imaging. Radiology 1999;210:558-62 CrossRef Medline

20. Lin DD, Kleinman JT, Wityk RJ, et al. Crossed cerebellar diaschisis in acute stroke detected by dynamic susceptibility contrast MR perfusion imaging. AJNR Am J Neuroradiol 2009;30:710-15 CrossRef Medline

21. Madai VI, Altaner A, Stengl KL, et al. Crossed cerebellar diaschisis after stroke: can perfusion-weighted MRI show functional inactivation? J Cereb Blood Flow Metab 2011;31:1493-500 CrossRef Medline

22. Chalela JA, Alsop DC, Gonzalez-Atavales JB, et al. Magnetic resonance perfusion imaging in acute ischemic stroke using continuous arterial spin labeling. Stroke 2000;31:680-87 CrossRef Medline

23. Detre JA, Leigh JS, Williams DS, et al. Perfusion imaging. Magn Reson Med 1992;23:37-45 CrossRef Medline

24. Noguchi T, Kawashima M, Irie H, et al. Arterial spin-labeling MR imaging in Moyamoya disease compared with SPECT imaging. Eur J Radiol 2011;80:e557-62 CrossRef Medline

25. Bokkers RP, Bremmer JP, van Berckel BN, et al. Arterial spin labeling perfusion MRI at multiple delay times: a correlative study with $\mathrm{H}(2)$ (15)O positron emission tomography in patients with symptomatic carotid artery occlusion. J Cereb Blood Flow Metab 2010;30: 222-29 CrossRef Medline

26. Chen S, Guan M, Lian HJ, et al. Crossed cerebellar diaschisis detected by arterial spin-labeled perfusion magnetic resonance imaging in subacute ischemic stroke. J Stroke Cerebrovasc Dis 2014;23: 2378-83 CrossRef Medline

27. Dai W, Garcia D, de Bazelaire C, et al. Continuous flow-driven inversion for arterial spin labeling using pulsed radio frequency and gradient fields. Magn Reson Med 2008;60:1488-97 CrossRef Medline

28. Garcia D, De Bazelaire C, Alsop D. Pseudo-continuous flow driven adiabatic inversion for arterial spin labeling. Proc Int Soc Magn Reson Med 2005;13:37

29. Mani S, Pauly J, Conolly S, et al. Background suppression with multiple inversion recovery nulling: applications to projective angiography. Magn Reson Med 1997;37:898-905 CrossRef Medline

30. Varoquaux A, Rager O, Lovblad KO, et al. Functional imaging of head and neck squamous cell carcinoma with diffusionweighted MRI and FDG PET/CT: quantitative analysis of ADC and SUV. Eur J Nucl Med Mol Imaging 2013;40:842-52 CrossRef Medline

31. Oppo K, Leen E, Angerson WJ, et al. Doppler perfusion index: an interobserver and intraobserver reproducibility study. Radiology 1998;208:453-57 CrossRef Medline

32. Wong CS, Gong N, Chu YC, et al. Correlation of measurements from diffusion weighted MR imaging and FDG PET/CT in GIST patients: ADC versus SUV. Eur J Radiol 2012;81:2122-26 CrossRef Medline

33. Seitz RJ, Azari NP, Knorr U, et al. The role of diaschisis in stroke recovery. Stroke 1999;30:1844-50 CrossRef Medline

34. Timmann D, Daum I. Cerebellar contributions to cognitive functions: a progress report after two decades of research. Cerebellum 2007;6:159-62 CrossRef Medline

35. Sui R, Zhang L. Cerebellar dysfunction may play an important role in vascular dementia. Med Hypotheses 2012;78:162-65 CrossRef Medline

36. Wolf RL, Detre JA. Clinical neuroimaging using arterial spin-la- 
beled perfusion magnetic resonance imaging. Neurotherapeutics 2007;4:346-59 CrossRef Medline

37. Uchihashi $Y$, Hosoda K, Zimine I, et al. Clinical application of arterial spin-labeling MR imaging in patients with carotid stenosis: quantitative comparative study with single-photon emission CT. AJNR Am J Neuroradiol 2011;32:1545-51 CrossRef Medline

38. Goetti R, O'Gorman R, Khan N, et al. Arterial spin labelling MRI for assessment of cerebral perfusion in children with moyamoya disease: comparison with dynamic susceptibility contrast MRI. Neuroradiology 2013;55:639-47 CrossRef Medline

39. Flint AC, Naley MC, Wright CB. Ataxic hemiparesis from strategic frontal white matter infarction with crossed cerebellar diaschisis. Stroke 2006;37:e1-2 CrossRef Medline

40. Infeld B, Davis SM, Lichtenstein M, et al. Crossed cerebellar diaschisis and brain recovery after stroke. Stroke 1995;26:90-95 CrossRef Medline

41. Miyazawa N, Toyama K, Arbab AS, et al. Evaluation of crossed cerebellar diaschisis in 30 patients with major cerebral artery occlusion by means of quantitative I-123 IMP SPECT. Ann Nucl Med 2001;15:513-19 CrossRef Medline
42. Wu WC, St Lawrence KS, Licht DJ, et al. Quantification issues in arterial spin labeling perfusion magnetic resonance imaging. Top Magn Reson Imaging 2010;21:65-73 CrossRef Medline

43. Momose T, Kosaka N, Nishikawa J, et al. Crossed cerebellar diaschisis in cerebrovascular disease detected by $\mathrm{N}$-isopropyl I-123 p-iodoamphetamine (I-123 IMP) with SPECT [in Japanese]. Kaku Igaku 1986;23:25-34 Medline

44. Kim J, Lee SK, Lee JD, et al. Decreased fractional anisotropy of middle cerebellar peduncle in crossed cerebellar diaschisis: diffusiontensor imaging-positron-emission tomography correlation study. AJNR Am J Neuroradiol 2005;26:2224-28 Medline

45. Greenberg JH, Kushner M, Rango M, et al. Validation studies of iodine-123-iodoamphetamine as a cerebral blood flow tracer using emission tomography. J Nucl Med 1990;31:1364-69 Medline

46. Inugami A, Kanno I, Uemura K, et al. Linearization correction of 99mTc-labeled hexamethyl-propylene amine oxime (HM-PAO) image in terms of regional CBF distribution: comparison to $\mathrm{C} 15 \mathrm{O} 2$ inhalation steady-state method measured by positron emission tomography. J Cereb Blood Flow Metab 1988;8:S52-60 CrossRef Medline 